\title{
Near-Five-Vector SVPWM Algorithm for Five-Phase Six-Leg Inverters under Unbalanced Load Conditions
}

\author{
Ping Zheng ${ }^{\dagger}$, Pengfei Wang ${ }^{*}$, Yi Sui ${ }^{*}$, Chengde Tong ${ }^{*}$, Fan Wu ${ }^{*}$, and Tiecai Li ${ }^{*}$ \\ $\dot{\dagger}^{*}$ Department of Electrical Engineering, Harbin Institute of Technology, Harbin, China
}

\begin{abstract}
Multiphase machines are characterized by high power density, enhanced fault-tolerant capacity, and low torque pulsation. For a voltage source inverter supplied multiphase machine, the probability of load imbalances becomes greater and unwanted low-order stator voltage harmonics occur. This paper deals with the PWM control of multiphase inverters under unbalanced load conditions and it proposes a novel near-five-vector SVPWM algorithm based on the five-phase six-leg inverter. The proposed algorithm can output symmetrical phase voltages under unbalanced load conditions, which is not possible for the conventional SVPWM algorithms based on the five-phase five-leg inverters. The cause of extra harmonics in the phase voltages is analyzed, and an $x y$ coordinate system orthogonal to the $\alpha \beta z$ coordinate system is introduced to eliminate low-order harmonics in the output phase voltages. Moreover, the digital implementation of the near-five-vector SVPWM algorithm is discussed, and the optimal approach with reduced complexity and low execution time is elaborated. A comparison of the proposed algorithm and other existing PWM algorithms is provided, and the pros and cons of the proposed algorithm are concluded. Simulation and experimental results are also given. It is shown that the proposed algorithm works well under unbalanced load conditions. However, its maximum modulation index is reduced by $5.15 \%$ in the linear modulation region, and its algorithm complexity and memory requirement increase. The basic principle in this paper can be easily extended to other inverters with different phase numbers.
\end{abstract}

Key words: Five-phase six-leg inverter, Multiphase machine drives, Near-five-vector space vector pulse width modulation (NFV-SVPWM), Unbalanced load conditions

\section{INTRODUCTION}

In the late 1960 s, multiphase machines were proposed to reduce the low frequency torque ripple in machine drives. Multiphase machines are characterized by enhanced fault tolerance, reduced per-phase converter rating, and low torque pulsation. Hence, significant efforts have been put into the development of multiphase drives since the late 1960s. In the 1990s, the inverter ac drives facilitated the utilization of multiphase machines. The research of multiphase drives started accelerating due to the developments of ship propulsion in the second half of the 1990s. In the last decade, multiphase machines have been attracting more and more attention in various applications including electric vehicles, "more electric" aircraft and ship propulsion [1]-[8].

Manuscript received May 14, 2013; revised Oct. 10, 2013

Recommended for publication by Associate Editor Sanjeet K. Dwivedi.

${ }^{\dagger}$ Corresponding Author: zhengping@hit.edu.cn

Tel: +86-451-86403086, Harbin Institute of Technology

*Dept. of Electrical Engineering, Harbin Institute of Technology, China
Taking the costs, the fault-tolerant capacity, and the occurrence probability of faults into account, the optimal phase number of a multiphase machine is five or six. In a five-phase machine supplied by a five-phase five-leg inverter, there are four control degrees of freedom, and the zero sequence component of the phase voltages is nonzero under unbalanced load conditions. By applying the decoupling (Clarke's) transformation, the original four-dimensional (4-D) stator system can be decomposed onto two two-dimensional (2-D) uncoupled planes and one zero sequence component. The $\alpha-\beta$ plane is identical to the corresponding plane for a three-phase machine. For a five-phase machine with distributed windings, the MMF distribution is near-sinusoidal. The other plane, named $x-y$, is not related to electromechanical energy conversion. The impedance for the $x-y$ stator current components is actually the stator winding leakage impedance. Thus, the applied voltages should contain minimum amplitude $x-y$ components in order to avoid large $x-y$ stator currents. For a five-phase machine with concentrated windings, the MMF 
distribution is quasi-rectangular. The current harmonics that map onto the $x-y$ plane can be utilized to couple with the corresponding spatial magnetic field harmonics to obtain additional average torque components [1], [8]-[11].

The conventional vector control and the direct torque control (DTC) which are applicable in three-phase machine drives, are also available in the multiphase drives. However, it is important to note that in multiphase drives, the low-order stator voltage harmonics that map onto the voltage $x-y$ plane should be avoided [12]. Therefore, a qualified method for inverter PWM control is required.

The current research related to the PWM control of multiphase inverters mainly focus on two-level inverters because they are simple and low-cost. This paper deals with the PWM control of multiphase two-level inverters, and the modulation strategies for multilevel inverters will not be discussed. The same as that for the three-phase machines, there are mainly two PWM methods: carrier-based PWM (CBPWM) and space vector PWM (SVPWM). The SVPWM algorithm facilitates digital implementation, and is characterized by a high modulation index and a constant switching frequency. Therefore, it is the most popular method [6], [7], [12]. Neglecting the resistor of the stator, the flux linkage space vector $\boldsymbol{\psi}_{\mathrm{s}}$ synthesized by the stator can be expressed as: $\boldsymbol{\psi}_{\mathrm{s}} \approx \int \mathbf{U}_{\mathrm{s}} d t$, where $\mathbf{U}_{\mathrm{s}}$ is the voltage space vector synthesized by the stator. Consequently, the symmetrical phase voltages are required in order to synthesize the circular rotating $\boldsymbol{\psi}_{\mathrm{s}}$. The above is the basic theory of the SVPWM algorithm.

The probability of load imbalances among phases becomes greater in multiphase machines as the number of phases increases. When an $n$-phase machine with a single neutral point is supplied by an $n$-phase n-leg inverter, the sum of the phase currents is constrained to be zero. It is not possible for the inverter to output $n$ symmetrical phase voltages under unbalanced load conditions because the potential of the neutral point of the machine cannot be controlled independently. Thus, the trajectory of the synthesized $\psi_{\mathrm{s}}$ is no longer circular under unbalanced load conditions.

A novel near-five-vector SVPWM (NFV-SVPWM) algorithm for five-phase machine drives is presented in this paper, which can output five symmetrical phase voltages under unbalanced load conditions. The proposed NFV-SVPWM algorithm applies to a five-phase six-leg inverter. The midpoint of the additional leg connects to the neutral point of the machine in the five-phase six-leg inverter. The effect of the switching vectors on the $x-y$ plane has been taken into account in the NFV-SVPWM algorithm and there are no low-order harmonics such as the $3 \mathrm{rd}$, 7th, etc. in its output phase voltages. Furthermore, the digital implementation of the NFV-SVPWM algorithm is investigated, and the optimal approach with reduced complexity and low execution time is elaborated. A comparison of the PWM techniques is given. The pros and

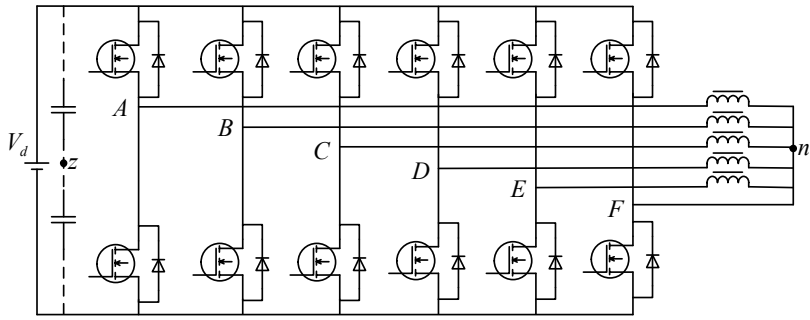

Fig. 1. Topology of five-phase six-leg inverter.

cons of the NFV-SVPWM algorithm are analyzed. Finally, simulation and experimental results validate the effectiveness of the proposed NFV-SVPWM algorithm. The basic principle in this paper can be easily extended to other inverters with different phase numbers.

\section{TOPOLOGY OF FIVE-PHASE SIX-LEG INVERTER}

SVPWM control under unbalanced load conditions is based on the five-phase six-leg inverter in this paper. Fig. 1 shows the topology of the five-phase six-leg inverter. The midpoint of the additional leg, F, connects to the neutral point of the loads in this topology. For the conventional five-phase five-leg inverter, the constraint that the sum of the phase currents need to be zero has to be satisfied and it is not possible for this topology to output five symmetrical phase voltages under unbalanced load conditions. In the five-phase six-leg inverter, the constraint releases, and the potential of the neutral point of the loads can be controlled independently. Consequently, with the help of the proposed topology, the zero sequence component of the output phase voltages can be controlled independently. There are five control degrees of freedom in the five-phase six-leg topology. The incremental control degree of freedom also diversifies the post-fault control strategies of the five-phase machines. Moreover, the five-phase six-leg topology does not require an access to the midpoint of the DC bus, and is able to accommodate certain open-circuit faults in the switches or machines [13]-[15]. These two advantages are not investigated in this paper.

\section{NEAR-FIVE-VECTORS SVPWM ALGORITHM}

In this section, a five-phase machine that adopts the distributed windings and symmetrical winding arrangement is taken as a practical example to explicate the principle of the NFV-SVPWM algorithm. The flow chart of the NFV-SVPWM algorithm is shown in Fig.2.

\section{A. Definition of Switching Vectors}

As shown in Fig. 1, $\mathrm{n}$ is the neutral point of the loads, $\mathrm{z}$ is the midpoint of the DC bus, and A, B, C, D, E, F are the midpoints of each leg, respectively. Note that, point $\mathrm{z}$ is defined to facilitate calculation, which does not exist in applications. The switching function is defined as $S_{i}$. When the upper switch of the corresponding leg is on, $S_{i}$ equals to 


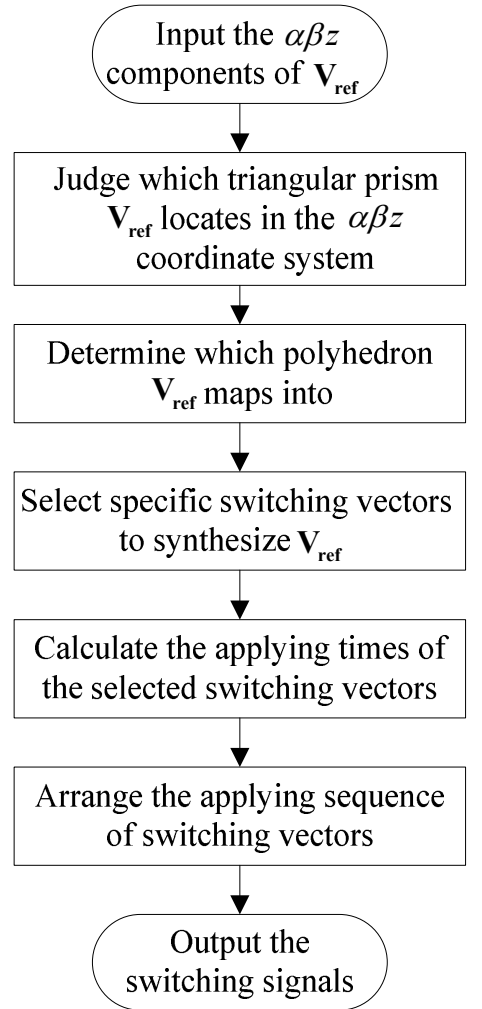

Fig. 2. Flow chart of NFV-SVPWM algorithm.

1. And $S_{i}$ equals to 0 when the lower switch is on. The leg voltage (the voltage between the midpoint of a leg and point z) of each phase can be calculated by

$$
V_{i z}=\left(2 S_{i}-1\right) \cdot \frac{V_{d}}{2}
$$

where $i=A, B, C, D, E, F$, and $V_{d}$ denotes the voltage of the DC bus.

The phase voltage (the voltage between the midpoint of a leg and point $\mathrm{n}$ ) is calculated by

$$
\left[\begin{array}{l}
V_{A n} \\
V_{B n} \\
V_{C n} \\
V_{D n} \\
V_{E n}
\end{array}\right]=\left[\begin{array}{llllll}
1 & 0 & 0 & 0 & 0 & -1 \\
0 & 1 & 0 & 0 & 0 & -1 \\
0 & 0 & 1 & 0 & 0 & -1 \\
0 & 0 & 0 & 1 & 0 & -1 \\
0 & 0 & 0 & 0 & 1 & -1
\end{array}\right] \cdot\left[\begin{array}{c}
V_{A z} \\
V_{B z} \\
V_{C z} \\
V_{D z} \\
V_{E z} \\
V_{F z}
\end{array}\right] .
$$

There are $2^{6}=64$ switching patterns for a five-phase six-leg inverter. Every switching pattern can be referred to as a six-digit binary number, each digit of which corresponds to $S_{F}, S_{A}, S_{B}, S_{C}, S_{D}, S_{E}$ in order.

The switching vectors of the five-phase six-leg inverter are defined in equation (3). Assuming that $\omega$ is the fundamental frequency of the output phase voltages, through the transform of (3), the $(10 \mathrm{k} \pm 1)$ th harmonics of the phase voltages can be equivalently expressed as circular rotating space vectors with the frequency of $(10 \mathrm{k} \pm 1) \omega$ in the stationary $\alpha \beta$ coordinate system, while the $(10 \mathrm{k} \pm 3)$ th harmonics of the phase voltages

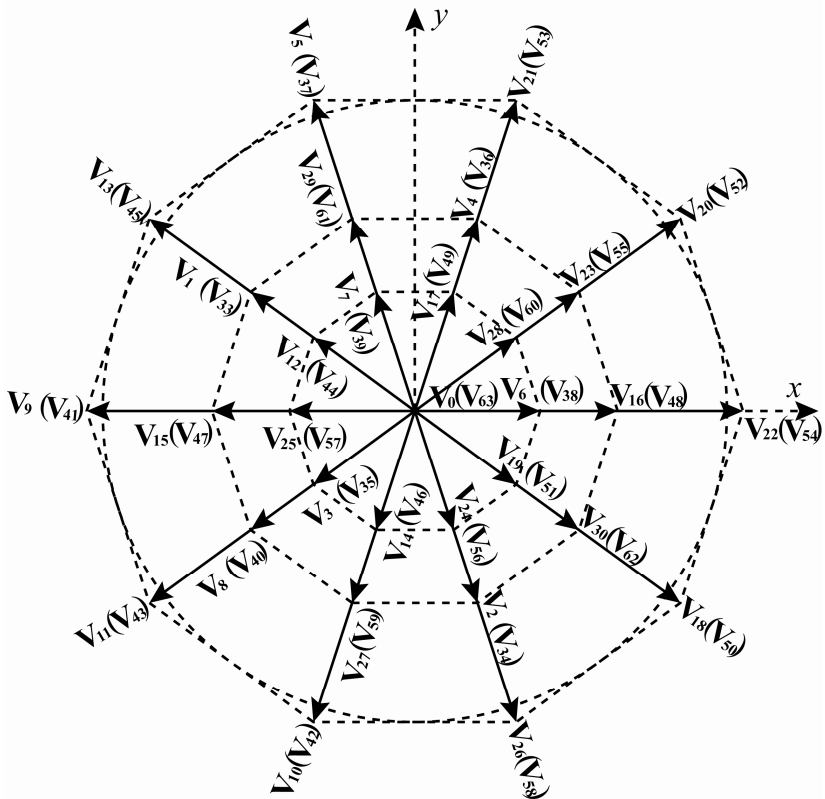

Fig. 3. Switching vectors in the $x y$ coordinate system.

can be equivalently expressed as circular rotating space vectors with the frequency of $(10 \mathrm{k} \pm 3) \omega$ in the stationary $x y$ coordinate system [16]-[20].

$\mathbf{V}_{k}=\left[\begin{array}{c}V_{\alpha}^{k} \\ V_{\beta}^{k} \\ V_{x}^{k} \\ V_{y}^{k} \\ V_{z}^{k}\end{array}\right]=\frac{2}{5}\left[\begin{array}{ccccc}1 & \cos \alpha & \cos 2 \alpha & \cos 3 \alpha & \cos 4 \alpha \\ 0 & \sin \alpha & \sin 2 \alpha & \sin 3 \alpha & \sin 4 \alpha \\ 1 & \cos 3 \alpha & \cos 6 \alpha & \cos 9 \alpha & \cos 12 \alpha \\ 0 & \sin 3 \alpha & \sin 6 \alpha & \sin 9 \alpha & \sin 12 \alpha \\ \frac{1}{2} & \frac{1}{2} & \frac{1}{2} & \frac{1}{2} & \frac{1}{2}\end{array}\right] \cdot\left[\begin{array}{c}V_{A n}^{k} \\ V_{B n}^{k} \\ V_{C n}^{k} \\ V_{D n}^{k} \\ V_{E n}^{k}\end{array}\right]$ (3) where $\alpha=\frac{2 \pi}{5}$ and $V_{\alpha}^{k}, V_{\beta}^{k}, V_{x}^{k}, V_{y}^{k}, V_{z}^{k}$ denote the $\alpha, \beta$, $x, y$ and zero sequence component of $\mathbf{V}_{k}$, respectively.

By the derivations above, a switching vector can be correlated with a space vector in the $\alpha \beta z$ coordinate system and a space vector in the $x y$ coordinate system. The distribution of switching vectors in the $x y$ coordinate system is shown in Fig. 3, and that in the $\alpha \beta z$ coordinate system is shown in Fig. 4. When the reference voltage space vector is known, particular switching vectors can be applied to synthesize it.

Fig. 5 shows the distribution of all the switching vectors in the 2-D stationary $\alpha \beta$ coordinate system with the exception of the zero sequence component. The switching vectors locate in ten sectors. Referring to the distribution of the switching vectors in the $\alpha \beta$ coordinate system, the space composed of the 64 switching vectors in the $\alpha \beta z$ coordinate system can be divided into ten triangular prisms. Furthermore, according to the magnitude of the switching vectors in the $\alpha \beta$ coordinate system, they can be classified into three patterns: large vectors, medium vectors, and small 


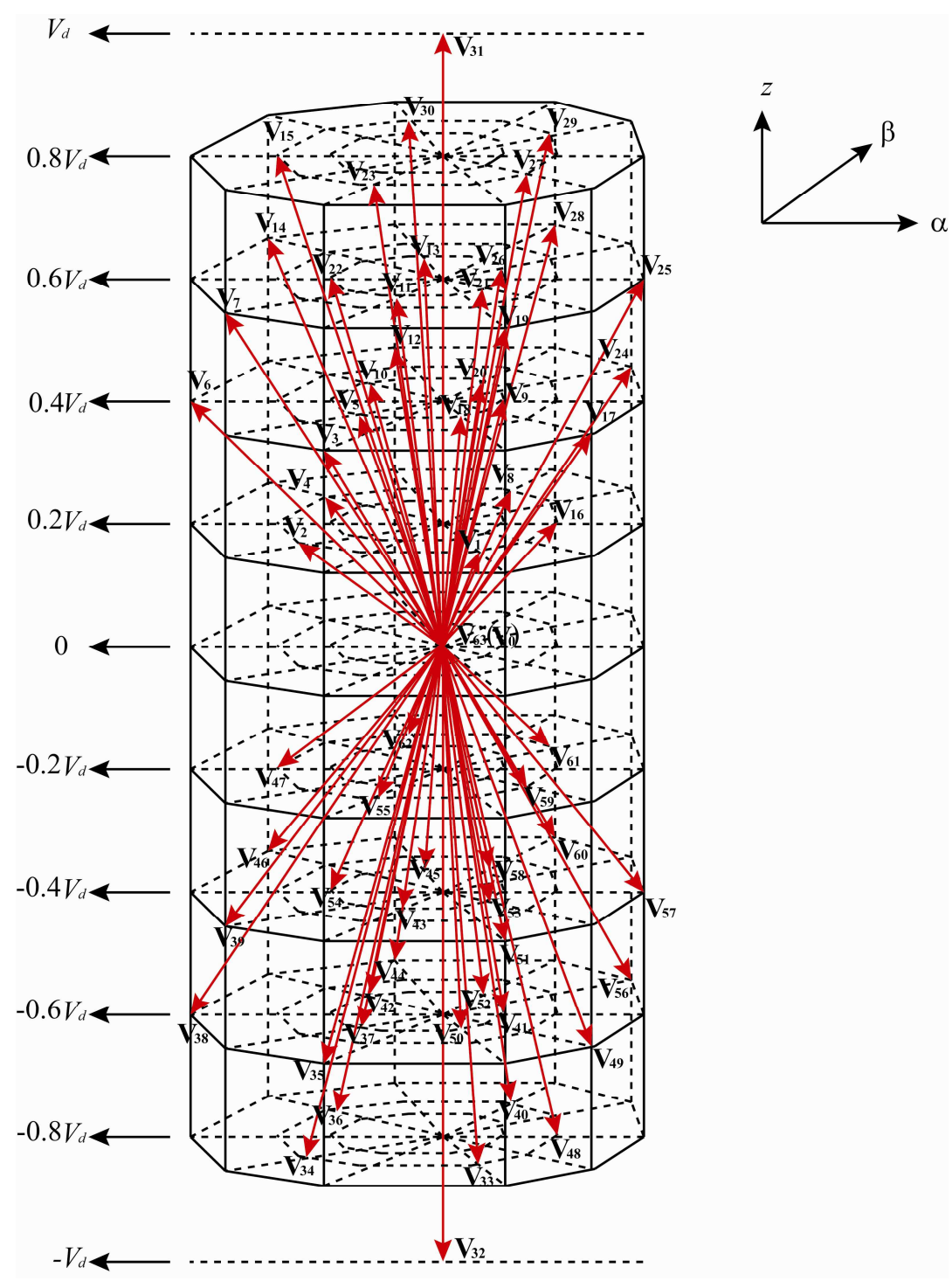

Fig. 4. Switching vectors in the $\alpha \beta z$ coordinate system.

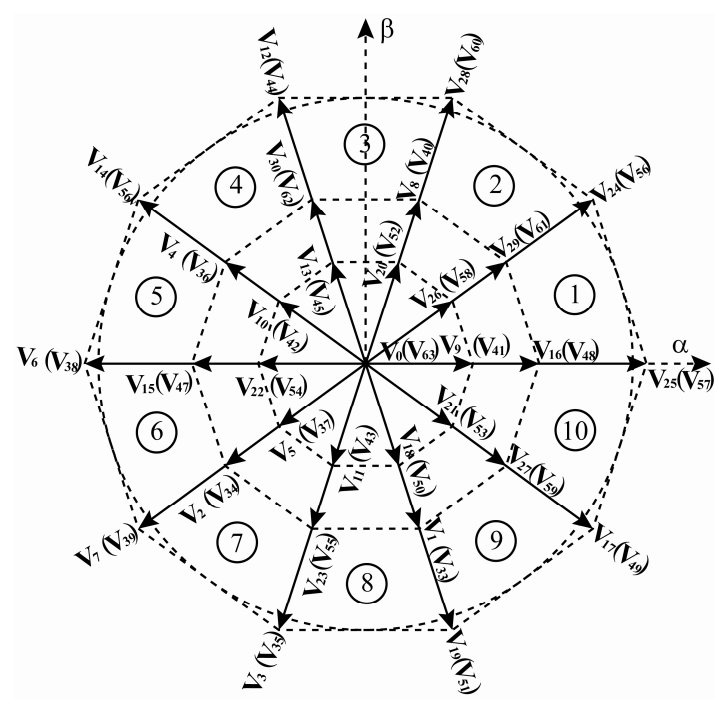

Fig. 5. Switching vectors in the $\alpha \beta$ coordinate system. vectors. When the small vectors are selected to synthesize the reference voltage space vector, the on-off frequency of the inverter during a PWM period doubles as the legs of the same switching state are not adjacent. Thus, the small vectors should not be selected in SVPWM control.

\section{B. Selection of Switching Vectors in NFV-SVPWM Algorithm}

The SVPWM algorithm is based on the principle of vector composition. The applying time of each switching vector must be no less than zero, and the sum of the applying times of the selected switching vectors must be no greater than a PWM period.

The NFV-SVPWM algorithm selects five nonzero switching vectors and two zero switching vectors as applying vectors in each PWM period. Once the combination of five nonzero switching vectors is fixed, the reference voltage vector $\mathbf{V}_{\text {ref }}$ that can be synthesized is confined to the 

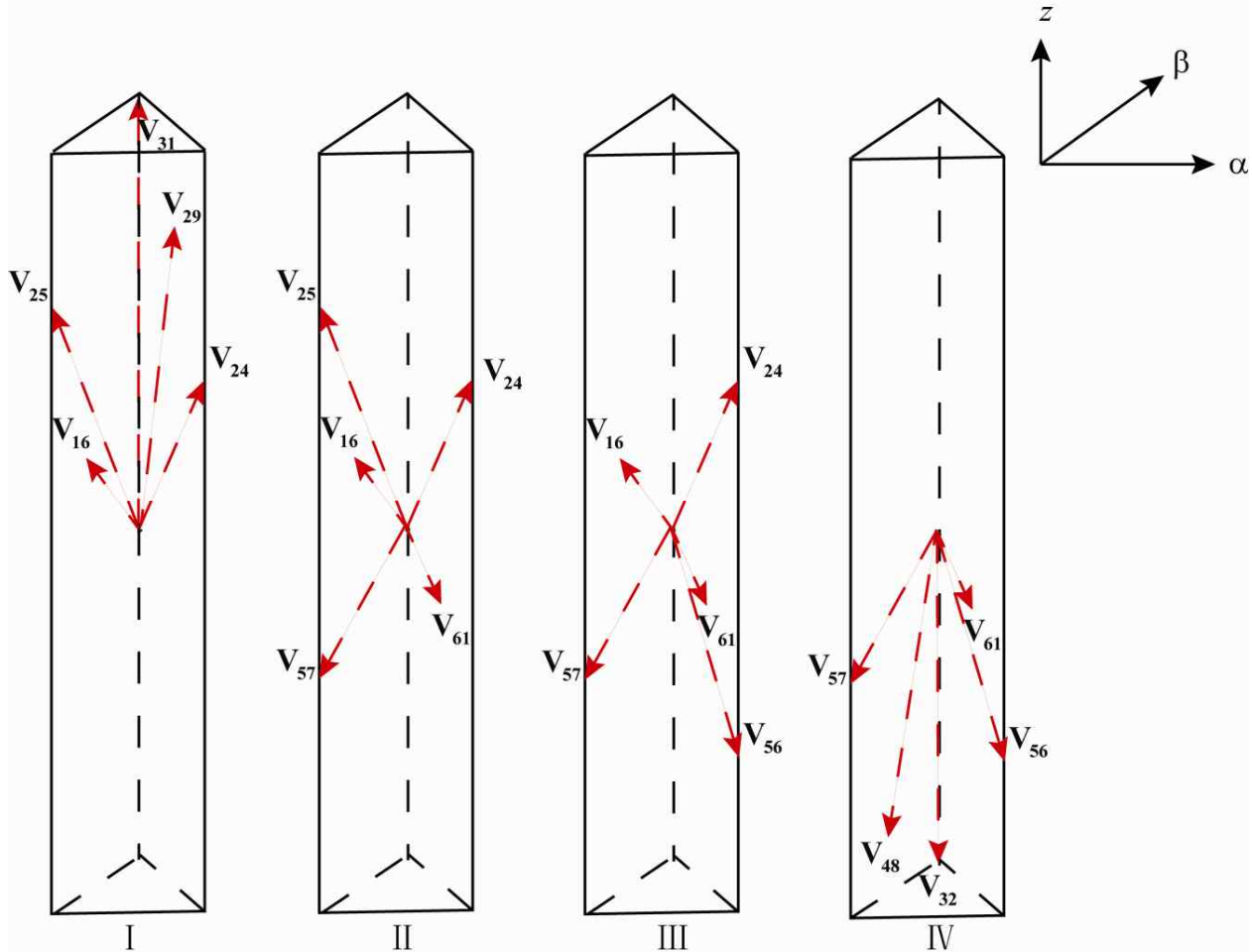

Fig. 6. Four combinations of nonzero switching vectors in triangular prism 1.

polyhedron composed of the five selected nonzero switching vectors. The following equation shows the relationship between $\mathbf{V}_{\text {ref }}$ and the applying vectors:

$$
T_{S} \mathbf{V}_{\text {ref }}=T_{k+2} \mathbf{V}_{\mathbf{k}+2}+T_{k+1} \mathbf{V}_{\mathbf{k}+1}+T_{k} \mathbf{V}_{\mathbf{k}}+T_{k-1} \mathbf{V}_{\mathbf{k}-1}+T_{k-2} \mathbf{V}_{\mathbf{k}-2}
$$

where $T_{S}$ is the PWM period, and $T_{k+2}, \cdots, T_{k-2}$ are the applying times of $\mathbf{V}_{k+2}, \cdots, \mathbf{V}_{k-2}$, respectively.

$$
\left[\begin{array}{c}
V_{A n}^{r} \\
V_{B n}^{r} \\
V_{C n}^{r} \\
V_{D n}^{r} \\
V_{E n}^{r}
\end{array}\right]=\left[\begin{array}{ccccc}
1 & 0 & 1 & 0 & \frac{\sqrt{2}}{2} \\
\cos \alpha & \sin \alpha & \cos 3 \alpha & \sin 3 \alpha & \frac{\sqrt{2}}{2} \\
\cos 2 \alpha & \sin 2 \alpha & \cos 6 \alpha & \sin 6 \alpha & \frac{\sqrt{2}}{2} \\
\cos 3 \alpha & \sin 3 \alpha & \cos 9 \alpha & \sin 9 \alpha & \frac{\sqrt{2}}{2} \\
\cos 4 \alpha & \sin 4 \alpha & \cos 12 \alpha & \sin 12 \alpha & \frac{\sqrt{2}}{2}
\end{array}\right] \cdot \mathbf{V}_{\text {ref }}
$$

The combination of the selected nonzero switching vectors varies with the location of $\mathbf{V}_{\text {ref }}$ in the $\alpha \beta z$ coordinate system, by which both the minimum on-off frequency and the maximum modulation index should be achieved. Therefore, the selected nonzero switching vectors should be adjacent.

The triangular prism in which $\mathbf{V}_{\text {ref }}$ locates and the polyhedron which $\mathbf{V}_{\text {ref }}$ maps into determine the combination of switching vectors. The triangular prism is judged by the $V_{\alpha}, V_{\beta}$ components of $\mathbf{V}_{\text {ref }}$, and the polyhedron is determined by the polarities of the phase voltages corresponding to $\mathbf{V}_{\text {ref }}$. There are four combinations of nonzero applying vectors in a triangular prism, each of which is composed of three large vectors and two medium vectors. The phase voltages that correspond to $\mathbf{V}_{\text {ref }}$ are calculated by equation (5). The digital implementation of the determination of the location of $\mathbf{V}_{\text {ref }}$ will be discussed in Section IV.

The judging conditions in triangular prism 1 are listed in Table I. The four combinations of nonzero switching vectors in triangular prism 1 are shown in Fig. 6. The judging conditions in other triangular prisms can be obtained by the same means.

For a five-phase machine with distributed windings, the expected $x-y$ components of $\mathbf{V}_{\text {ref }}$ are zero. For a five-phase machine with concentrated windings, it is possible to obtain additional average torque components by taking advantage of the harmonics that map onto the $x-y$ plane. Furthermore, the zero component of $\mathbf{V}_{\text {ref }}$ is required to be zero in the vector control for multiphase drives under normal conditions, and it is possible that the expected zero component of $\mathbf{V}_{\text {ref }}$ is nonzero under post-fault conditions.

A five-phase machine that adopts the distributed windings and symmetrical winding arrangement is used as a practical example throughout this paper, and therefore the expected $x-y$ 
TABLE I

Judging Conditions of NFV-SVPWM ALgorithm IN TRIANgular PRISM 1

\begin{tabular}{|c|c|c|c|c|}
\hline \multicolumn{3}{|c|}{ Judging conditions } & \multirow{2}{*}{ Location of $\mathbf{V}_{\text {ref }}$} & Combination of nonzero switching vectors \\
\cline { 1 - 2 }$V_{A n}^{r}$ & $V_{C n}^{r}$ & $V_{E n}^{r}$ & \\
\hline$\geq 0$ & $\geq 0$ & $\geq 0$ & Polyhedron I & $\mathbf{V}_{25}, \mathbf{V}_{24}, \mathbf{V}_{31}, \mathbf{V}_{16}, \mathbf{V}_{29}$ \\
\hline$\geq 0$ & $\leq 0$ & $\geq 0$ & Polyhedron II & $\mathbf{V}_{25}, \mathbf{V}_{24}, \mathbf{V}_{57}, \mathbf{V}_{16}, \mathbf{V}_{61}$ \\
\hline$\geq 0$ & $\leq 0$ & $\leq 0$ & Polyhedron III & $\mathbf{V}_{24}, \mathbf{V}_{56}, \mathbf{V}_{57}, \mathbf{V}_{16}, \mathbf{V}_{61}$ \\
\hline$\leq 0$ & $\leq 0$ & $\leq 0$ & Polyhedron IV & $\mathbf{V}_{56}, \mathbf{V}_{57}, \mathbf{V}_{32}, \mathbf{V}_{61}, \mathbf{V}_{48}$ \\
\hline
\end{tabular}

components of $\mathbf{V}_{\text {ref }}$ are zero. The basic concepts in this paper can also be applied to the machines with different structures.

\section{Applying Times of Switching Vectors in NFV-SVPWM Algorithm}

In this part, it is assumed that $\mathbf{V}_{\text {ref }}$ maps into the polyhedron $\mathrm{I}$ of the triangular prism 1 in the $\alpha \beta z$ coordinate system to make a concrete illustration of the NFV-SVPWM algorithm. In that case, $V_{25}, V_{24}, V_{31}, V_{16}, V_{29}$ are selected as nonzero switching vectors in the NFV-SVPWM algorithm.

The distribution of the preferred switching vectors in the $x y$ coordinate system is shown in Fig. $7 . \mathbf{V}_{\mathbf{3 1}}$ corresponds to a zero space vector in the $x y$ coordinate system. The orientation of $\mathbf{V}_{25}$ is opposite to that of $\mathbf{V}_{16}$, and the orientation of $\mathbf{V}_{24}$ is opposite to that of $\mathbf{V}_{29}$. For a machine with distributed windings, the expected $x-y$ components of $\mathbf{V}_{\text {ref }}$ are zero. In the $x y$ coordinate system, the distribution of the selected switching vectors is utilized to achieve that the synthesis of the applying vectors is zero.

If the following constraint conditions are satisfied, the synthesis of the applying vectors in the $x y$ coordinate system will be zero, and there will be no $(10 \mathrm{k} \pm 3)$ th harmonics in the output phase voltages.

$$
\frac{T_{16}}{T_{25}}=\frac{\left|\mathbf{V}_{\mathbf{S}}\right|}{\left|\mathbf{V}_{\mathbf{M}}\right|}, \frac{T_{29}}{T_{24}}=\frac{\left|\mathbf{V}_{\mathbf{S}}\right|}{\left|\mathbf{V}_{\mathbf{M}}\right|},
$$

where $\left|\mathbf{V}_{\mathbf{S}}\right|$ and $\left|\mathbf{V}_{\mathbf{M}}\right|$ denote the magnitudes of the small vector and medium vector, respectively. Both $\left|\mathbf{V}_{\mathbf{S}}\right|$ and $\left|\mathbf{V}_{\mathbf{M}}\right|$ are constants.

Based on the analysis above, the applying times of the switching vectors in the NFV-SVPWM algorithm are obtained by solving equations

$$
\left\{\begin{array}{l}
\mathbf{V}_{\text {ref }} T_{S}=\mathbf{V}_{25} T_{25}+\mathbf{V}_{24} T_{24}+\mathbf{V}_{31} T_{31}+\mathbf{V}_{29} T_{29}+\mathbf{V}_{16} T_{16} \\
\frac{T_{16}}{T_{25}}=\frac{T_{29}}{T_{24}}=0.618=\lambda
\end{array} .\right.
$$

Additionally, two zero switching vectors $\mathbf{V}_{0}, \mathbf{V}_{63}$ are also applied in each PWM period to avoid a discontinuous modulation.

Assuming that $T_{\text {sum }}=T_{25}+T_{24}+T_{31}+T_{29}+T_{16} \quad$, an overmodulation occurs when $T_{\text {sum }}>T_{s}$. In that case, the applying times of $\mathbf{V}_{\mathbf{0}}, \mathbf{V}_{\mathbf{6 3}}$ equal to zero, and in order to reduce the distortion of the output phase voltages to its least extent, the synthesis of the switching vectors should maintain the orientation of the reference voltage vector. Therefore, the solution of equation (7) should be normalized before it can be utilized to generate switching signals. The normalization of the solution is shown as follows:

$$
\left[\begin{array}{c}
T_{25}^{\prime} \\
T_{24}^{\prime} \\
T_{31}^{\prime} \\
T_{29}^{\prime} \\
T_{16}^{\prime}
\end{array}\right]=\frac{1}{T_{\text {sum }}}\left[\begin{array}{l}
T_{25} \\
T_{24} \\
T_{31} \\
T_{29} \\
T_{16}
\end{array}\right] .
$$

When $T_{\text {sum }} \leq T_{s}$, the solution of equation (7) can be utilized to generate the switching signals without any modification. The applying times of $\mathbf{V}_{\mathbf{0}}, \mathbf{V}_{\mathbf{6 3}}$ are calculated by

$$
T_{0}=T_{63}=\frac{T_{S}-T_{\text {sum }}}{2}
$$

In order to reduce the total harmonic distribution (THD) of the phase voltage, a symmetrical switching sequence is adopted to generate the switching signals in the NFV-SVPWM algorithm. In polyhedron I of triangular prism 1, the switching sequence is arranged as $V_{0}-V_{16}-V_{24}-V_{25}-V_{29}-V_{31}-V_{63}-V_{63}-V_{31}-V_{29}-V_{25}-V_{24}-$ $\mathbf{V}_{16}-\mathbf{V}_{\mathbf{0}}$ in order. The resultant switching signals are shown in Fig. 8.

\section{DIGITAL IMPLEMENTATION OF NFV-SVPWM ALGORITHM}

Two of the steps in the NFV-SVPWM algorithm are time-consuming: the determination of the location of $\mathbf{V}_{\text {ref }}$ 


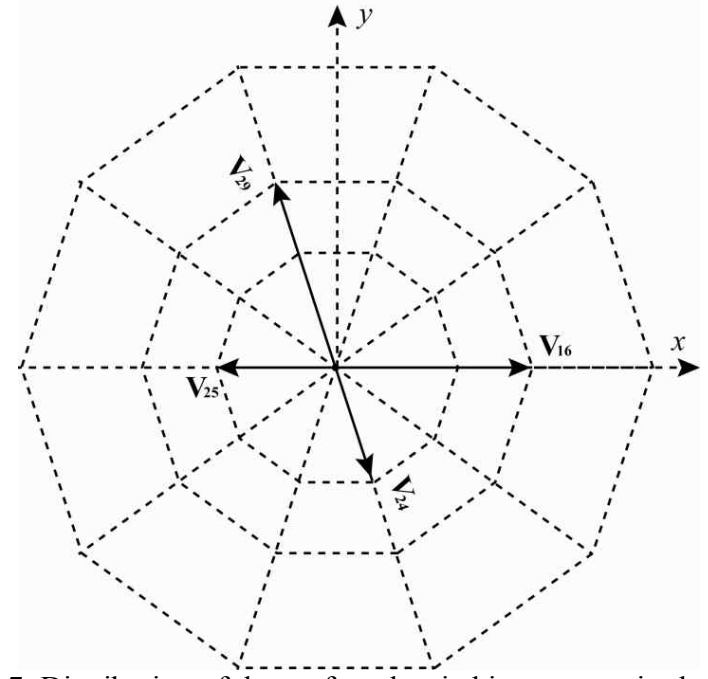

Fig. 7. Distribution of the preferred switching vectors in the $x y$ coordinate system.

and the calculation of the applying times of the switching vectors. The intensive computations required in these two steps hinder the online application of the NFV-SVPWM algorithm. In this section, the maximal offline calculation of the NFV-SVPWM algorithm has been investigated.

\section{A. Determination of the location of $\mathbf{V}_{\text {ref }}$}

Firstly, the triangular prism in which $\mathbf{V}_{\text {ref }}$ locates is determined. Then the polyhedron which $\mathbf{V}_{\text {ref }}$ maps into is judged. The first procedure is realized according to the $V_{\alpha}, V_{\beta}$ components of $\mathbf{V}_{\text {ref }}$. The second procedure is determined according to the polarities of the phase voltages corresponding to $\mathbf{V}_{\text {ref }}$.

$$
\left\{\begin{array}{l}
U_{0}=V_{\beta}^{r} \\
U_{1}=V_{\alpha}^{r} \sin \frac{\pi}{5}-V_{\beta}^{r} \cos \frac{\pi}{5} \\
U_{2}=V_{\alpha}^{r} \cos \frac{\pi}{10}-V_{\beta}^{r} \sin \frac{\pi}{10} \\
U_{3}=V_{\alpha}^{r} \sin \frac{\pi}{5}+V_{\beta}^{r} \cos \frac{\pi}{5} \\
U_{4}=V_{\alpha}^{r} \cos \frac{\pi}{10}+V_{\beta}^{r} \sin \frac{\pi}{10}
\end{array}\right.
$$

Five temporary variables are defined in equation (10). In the $\alpha \beta$ coordinate system, the sector which $\mathbf{V}_{\text {ref }}$ maps into is determined by the value of the sector-determination function. The sector-determination function is shown as follows:

$$
\begin{aligned}
S= & \operatorname{sign}\left(U_{0}\right)+4 \operatorname{sign}\left(U_{1}\right)+2 \operatorname{sign}\left(U_{2}\right)+4 \operatorname{sign}\left(-U_{3}\right) \\
& +4 \operatorname{sign}\left(-U_{4}\right)
\end{aligned}
$$

where $\operatorname{sign}(\cdot)$ is the sign function. The value of $\operatorname{sign}(\cdot)$ equals to 1 when the independent variable is greater than zero, otherwise it is zero.

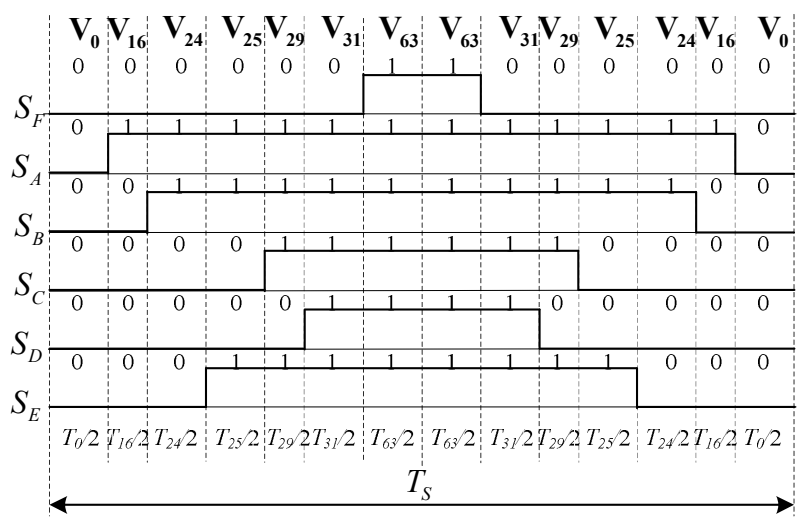

Fig. 8. Switching signals when $\mathbf{V}_{\text {ref }}$ locates in polyhedron I of triangular prism 1 .

A sector in the $\alpha \beta$ coordinate system corresponds to the triangular prism of the same number in the $\alpha \beta z$ coordinate system. Thus, the triangular prism in which $\mathbf{V}_{\text {ref }}$ locates can be judged by the value of the function $S$. The corresponding relationships between the triangular prism number and function $S$ are shown in Table II.

The polyhedron which $\mathbf{V}_{\text {ref }}$ maps into is judged by the polarities of the phase voltages corresponding to $\mathbf{V}_{\text {ref }}$. There are four polyhedrons in a triangular prism. As shown in Table I, only three of the phase voltages are required to determine the polyhedron. In triangular prism 1, the three phase voltages for the polyhedron determination are calculated by (12), and unnecessary calculation is avoided.

$$
\left[\begin{array}{c}
V_{A n}^{r} \\
V_{C n}^{r} \\
V_{E n}^{r}
\end{array}\right]=\left[\begin{array}{ccccc}
1 & 0 & 1 & 0 & \frac{\sqrt{2}}{2} \\
\cos 2 \alpha & \sin 2 \alpha & \cos 6 \alpha & \sin 6 \alpha & \frac{\sqrt{2}}{2} \\
\cos 4 \alpha & \sin 4 \alpha & \cos 12 \alpha & \sin 12 \alpha & \frac{\sqrt{2}}{2}
\end{array}\right] \cdot \mathbf{V}_{\text {ref }} .
$$

\section{B. Calculation of the applying times of switching vectors}

In this part, it is also assumed that $\mathbf{V}_{\text {ref }}$ maps into polyhedron I of triangular prism 1 in the $\alpha \beta z$ coordinate system to explain the reduction of the arithmetic operations in the NFV-SVPWM algorithm. The applying times of the nonzero switching vectors are calculated by

$$
\begin{aligned}
{\left[\begin{array}{lllll}
T_{25} & T_{24} & T_{31} & T_{29} & T_{16}
\end{array}\right]^{T}=} & {\left[\begin{array}{lllll}
\mathbf{V}_{25} & \mathbf{V}_{24} & \mathbf{V}_{31} & \mathbf{V}_{29} & \mathbf{V}_{16}
\end{array}\right]^{-1} . } \\
& \cdot \mathbf{V}_{\text {ref }} \cdot T_{S}
\end{aligned}
$$

In equation (13), the calculation of the inverse matrix of the five-order matrix requires a large amount of arithmetic operations. Calculating it offline and then applying the results online provides a possible means to employ the NFV-SVPWM algorithm online. However, it is difficult to obtain the analytical solution of the inverse matrix of a 
TABLE II

Corresponding Relationships between The Triangular Prism Number and Function $S$

\begin{tabular}{|c|c|c|c|c|c|c|c|c|c|c|}
\hline $\begin{array}{c}\text { Triangular prism } \\
\text { number }\end{array}$ & 1 & 2 & 3 & 4 & 5 & 6 & 7 & 8 & 9 & 10 \\
\hline$S$ & 7 & 3 & 1 & 5 & 9 & 8 & 12 & 14 & 10 & 6 \\
\hline
\end{tabular}

TABLE III

Eight CONSTANTS CONSISTED In MATRIX $A$

\begin{tabular}{|c|c|c|c|c|c|c|c|}
\hline$K_{1}$ & $K_{2}$ & $K_{3}$ & $K_{4}$ & $K_{5}$ & $K_{6}$ & $K_{7}$ & $K_{8}$ \\
\hline 1.1181 & 0.8090 & 1.8091 & 0.3090 & 1.9022 & 1.5389 & 0.5878 & 0.9511 \\
\hline
\end{tabular}

TABLE IV

COEFFicients of Matrix $A$ In Triangular Prism 1

\begin{tabular}{|c|c|c|c|c|c|c|c|c|c|}
\hline & $A_{11}$ & $A_{12}$ & $A_{13}$ & $A_{21}$ & $A_{22}$ & $A_{23}$ & $A_{31}$ & $A_{32}$ & $A_{33}$ \\
\hline Polyhedron I & $K_{5}$ & 0 & 0 & $-K_{6}$ & $K_{1}$ & 0 & $-K_{7}$ & $-K_{2}$ & 1 \\
\hline Polyhedron II & $K_{5}$ & 0 & 0 & $-K_{8}$ & $K_{4}$ & 1 & $-K_{7}$ & $K_{2}$ & -1 \\
\hline Polyhedron III & $K_{4}$ & $K_{8}$ & 1 & $-K_{4}$ & $K_{8}$ & -1 & $K_{1}$ & $-K_{6}$ & 0 \\
\hline Polyhedron IV & -1 & 0 & -1 & 0 & $K_{5}$ & 0 & $K_{1}$ & $-K_{6}$ & 0 \\
\hline
\end{tabular}

five-order matrix. For a five-phase machine with distributed windings, the expected $x-y$ components of $\mathbf{V}_{\text {ref }}$ are zero. As shown in Fig. 7, the distribution of the preferred switching vectors in the $x y$ coordinate system is utilized to reduce the calculation of equation (13). If the constraint conditions in (6) are satisfied, the synthesis of applying vectors in the $x y$ coordinate system will be zero. Then, the applying times of $\mathbf{V}_{25}, \mathbf{V}_{24}, \mathbf{V}_{31}$ are calculated by

$$
\begin{aligned}
{\left[\begin{array}{lll}
T_{25} & T_{24} & T_{31}
\end{array}\right]^{T} \frac{1}{T_{S}}=} & {\left[\begin{array}{lll}
\mathbf{V}_{25}^{\alpha \beta z}+\lambda \mathbf{V}_{\mathbf{1 6}}^{\alpha \beta z} & \mathbf{V}_{\mathbf{2 4}}^{\alpha \beta z}+\lambda \mathbf{V}_{\mathbf{1 6}}^{\alpha \beta z} & \mathbf{V}_{\mathbf{3 1}}^{\alpha \beta z}
\end{array}\right]^{-1} } \\
& \cdot \mathbf{V}_{\mathrm{ref}}^{\alpha \beta z}
\end{aligned}
$$

where $\mathbf{V}_{\mathbf{k}}^{\alpha \beta z}$ denotes the $\alpha \beta z$ components of $\mathbf{V}_{\mathbf{k}}$.

The applying times of the other two nonzero switching vectors can be obtained through equations in (6). The order of the inverse matrix is reduced to three. Compared with equation (13), the calculation in equation (14) has been significantly cut down. Moreover, it is relatively easy to obtain the analytical solution of the inverse matrix.

Assuming that $A$ denotes the inverse matrix in equation (14), matrix $A$ varies with the location of $\mathbf{V}_{\text {ref }}$. There are forty combinations of non-zero applying vectors, each of which corresponds to a certain matrix $A$. A detailed analysis shows that all these coefficients of matrix $A$ are made from the reduced set of eight constants. The eight constants are listed in Table III, and the coefficients of matrix $A$ in triangular prism 1 are shown in Table IV.
This analysis cuts down the arithmetic operations of the NFV-SVPWM algorithm and facilitates its digital implementation.

\section{COMPARISON WITH EXISTING PWM ALGORITHMS}

As mentioned in Section I, the CBPWM and SVPWM algorithms are the main approaches in the PWM control of multiphase inverters. According to [1], the CBPWM with zero-sequence injection and the SVPWM are exact equivalents in the PWM of multiphase voltage source inverters. With an optimization of the space vector sequence, full dc bus utilization and stator current ripple minimization can be achieved by both algorithms. The published SVPWM strategies are mainly based on $(4 \mathrm{~L})$ and $(2 \mathrm{~L}+2 \mathrm{M})$ methods. The (4L) SVPWM algorithm adopts four large nonzero switching vectors per switching period to synthesize $\mathbf{V}_{\text {ref }}$ while the $(2 \mathrm{~L}+2 \mathrm{M})$ SVPWM algorithm adopts two large and two medium nonzero switching vectors per switching period to synthesize $\mathbf{V}_{\text {ref }}$. They provide the same utilization of the dc bus voltage in the linear modulation region. The (4L) SVPWM algorithm leads to a smaller phase voltage THD on the $x-y$ plane, but its total phase voltage THD is higher than the corresponding one of the $(2 \mathrm{~L}+2 \mathrm{M})$ SVPWM algorithm. The (4L) SVPWM algorithm will always generate higher current THD and squared rms current ripple at the equal 
average switching frequency than the $(2 \mathrm{~L}+2 \mathrm{M})$ SVPWM algorithm, and its implementation is more difficult [18], [19].

The existing SVPWM approaches mostly apply to the two-level five-phase five-leg inverters. It is not possible for them to output five symmetrical phase voltages under unbalanced load conditions since the zero sequence component of the phase voltages cannot be controlled independently. By contrast, the NFV-SVPWM algorithm applied to the five-phase six-leg inverters can control the zero sequence component of the phase voltages independently and it can output five symmetrical phase voltages under unbalanced load conditions. The NFV-SVPWM algorithm is built on the $(2 \mathrm{~L}+2 \mathrm{M})$ SVPWM algorithm. Thus, their switching characteristics are identical. The performances of $(2 \mathrm{~L}+2 \mathrm{M})$ SVPWM algorithm are the same as those of the CBPWM with zero-sequence injection. In addition, it is superior in in terms of switching characteristics when compared with the (4L) SVPWM algorithm. Accordingly, the $(2 \mathrm{~L}+2 \mathrm{M})$ SVPWM algorithm is chosen for comparison with the NFV-SVPWM algorithm in this section. Note that, the $(2 \mathrm{~L}+2 \mathrm{M})$ SVPWM algorithm is denoted further as $4 \mathrm{~V}-\mathrm{SVPWM}$ for conciseness.

Table $\mathrm{V}$ provides a comparison of the major characteristics of the 4V-SVPWM and NFV-SVPWM algorithms.

The maximum modulation index $M$ is defined as $M=V_{1} /\left(V_{d} / 2\right)$, where $V_{1}$ is the maximum fundamental peak phase voltage. The value of $M$ in table $\mathrm{V}$ is calculated in the linear modulation region. For the NFV-SVPWM algorithm, $M$ relates to the zero sequence component of $\mathbf{V}_{\text {ref }}$. However, it is possible to obtain the value of $M$ when the zero sequence component of $\mathbf{V}_{\text {ref }}$ equals to zero. The calculation procedure is given in Appendix A.

The THD of phase voltage $i$ is defined as

$$
\mathrm{THD}_{i}=\sqrt{\sum_{k=2}^{h} F_{k}^{2}} / F_{1}
$$

where $F_{k}$ stands for the $k$ th component in the spectrum of the phase voltage $i$, and h represents the harmonic order closest to the uppermost frequency in calculation. The phase voltage THD in Table $\mathrm{V}$ has been calculated up to $3 \mathrm{kHz}$ on the basis of the experimental results (given in Section VII). The PWM switching frequency is set to $13.2 \mathrm{kHz}$ in the experiments, and the current ripple is negligible at such a high switching frequency. Moreover, the switching characteristics of the NFV-SVPWM and 4V-SVPWM algorithms are the same. Thus, the switching characteristics are not listed in Table V.

The complexity of the algorithms has been analyzed by comparing the number of program statements executed in a switching period, and the memory requirement has been evaluated by the number of constants and variables stored in the memory. The data in Table $\mathrm{V}$ depend on how the algorithms have been carried out. Nevertheless, it can be
TABLE V

MAIN CHARACTERISTICS OF THE COMPARED SVPWM STRATEGIES

\begin{tabular}{|c|c|c|}
\hline & 4V-SVPWM & NFV-SVPWM \\
\hline $\begin{array}{c}\text { Maximum modulation } \\
\text { index }\end{array}$ & 1.0515 & 1 \\
\hline Phase voltage THD & 0.01823 & 0.01490 \\
\hline Tackle unbalanced load & no & yes \\
\hline Algorithm complexity & 45 & 61 \\
\hline Memory requirement & 23 & 43 \\
\hline
\end{tabular}

inferred that the NFV-SVPWM algorithm is a little more complex than the 4V-SVPWM algorithm.

To sum up, the switching characteristics and voltage THD of the NFV-SVPWM algorithm are as good as those of 4V-SVPWM algorithm and the NFV-SVPWM algorithm is able to output five symmetrical phase voltages under unbalanced load conditions. However, the maximum modulation index of the NFV-SVPWM algorithm is reduced by $5.15 \%$ in the linear modulation region, and its algorithm complexity and memory requirement increase.

\section{SimULATION RESUlTS}

A Matlab/Simulink simulation environment has been designed to validate the effectiveness of the proposed NFV-SVPWM algorithm. The performances of two algorithms under unbalanced load conditions are compared: the 4V-SVPWM algorithm based on a five-phase five-leg inverter and the NFV-SVPWM algorithm.

The $\mathbf{V}_{\text {ref }}$ of both algorithms on the $\alpha \beta$ plane are space vectors with a magnitude of $8.5 \mathrm{~V}$, rotating at $518.1 \mathrm{rad} / \mathrm{s}$, and their expected $x-y$ components are zero. There is no zero sequence component of $\mathbf{V}_{\text {ref }}$ in the 4V-SVPWM algorithm since the 4V-SVPWM algorithm cannot control the zero sequence component of the output phase voltages independently. The expected zero sequence component of the NFV-SVPWM algorithm is zero. Four $5 \mathrm{ohm}$ resistors connected in a star connection constitute the loads of phase A, $\mathrm{B}, \mathrm{C}$, and $\mathrm{E}$, while phase $\mathrm{D}$ is open-circuit in order to test the performances of the SVPWM algorithms under extreme unbalance load conditions. Fig. 9 illustrates the simulation results. For the 4V-SVPWM algorithm, the $x-y$ components of the output phase voltages are zero, but the amplitudes of the output phase voltages differ drastically. It is obvious that the $4 \mathrm{~V}$-SVPWM algorithm is unable to output symmetrical phase voltages under unbalanced load conditions because it cannot control the zero sequence component of the phase voltages independently. By contrast, the proposed NFV-SVPWM algorithm can output symmetrical phase voltages under unbalanced load conditions. Both the $x-y$ components and the zero sequence component of the output phase voltages are zero, and there are no $3 \mathrm{rd}$, 7th, etc. 

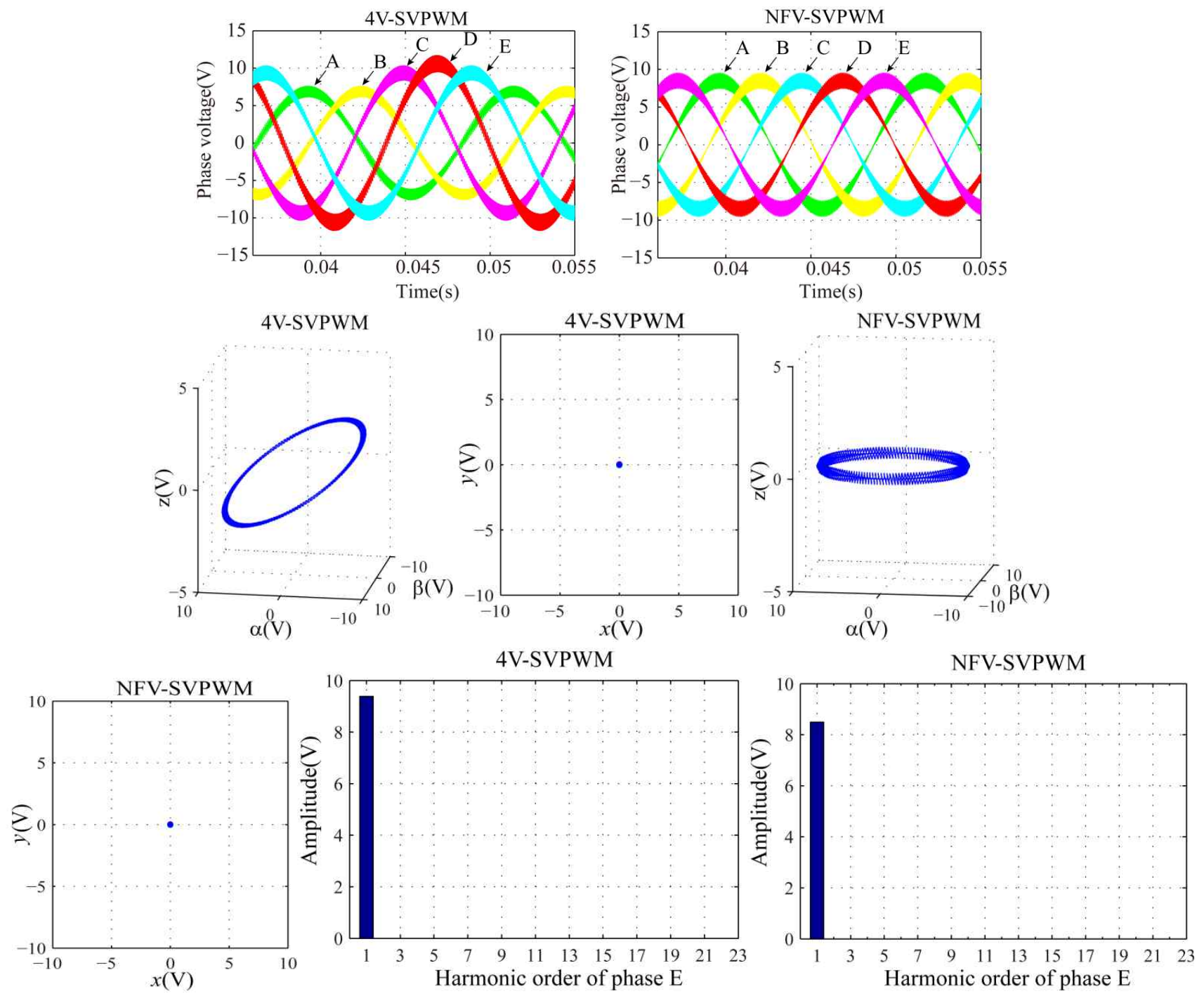

Fig. 9. Simulation results for $\mathbf{V}_{\text {ref }}=8.5 \mathrm{e}^{j \omega t}(\mathrm{~V}), \omega=518.1(\mathrm{rad} / \mathrm{s})$ under unbalanced load conditions. From left to right: 4V-SVPWM, NFV-SVPWM. From top to bottom: output phase voltages, voltage trajectory in the $\alpha \beta z$ coordinate system and $x y$ coordinate system, and voltage harmonic distribution of phase $\mathrm{E}$.

harmonics in the output phase voltages. Note that, the phase voltages in Fig. 9 are filtered by low-pass filters with the same cutoff frequency of $3 \mathrm{kHz}$ to facilitate observation.

\section{EXPERIMENTAL RESULTS}

An experimental bench has been built in the laboratory. The experimental bench is comprised of four parts: the voltage source inverter (VSI), the control unit, the switching devices, and the loads. A three-phase uncontrolled rectifier paralleling with filter capacitors works as the VSI of the system. The SVPWM algorithms are fully digitally implemented by a control board based on a fixed-point digital signal processor (DSP) TMS320F2812. Two intelligent power modules (IPMs) act as the switching devices of the five-phase PWM inverter.
By connecting the output of leg $\mathrm{F}$ to the neutral point of the loads, the six legs build a five-phase six-leg inverter, which the NFV-SVPWM algorithm is based on. By disconnecting the neutral point of the loads from the output of leg $\mathrm{F}$, the remaining five legs build a five-phase five-leg inverter, which the $4 \mathrm{~V}$-SVPWM algorithm is based on. The load parameters in the experiments are identical to those in the simulations: the loads of phase A, B, C, and E are composed of four 5 ohm resistors connected in star connection, while the phase D is open-circuit.

The $\mathbf{V}_{\text {ref }}$ of both algorithms on the $\alpha \beta$ plane is a space vector with a magnitude of $8.5 \mathrm{~V}$, rotating at $518.1 \mathrm{rad} / \mathrm{s}$, and the $x$-y components of $\mathbf{V}_{\text {ref }}$ are zero. Additionally, the zero component of $\mathbf{V}_{\text {ref }}$ of the NFV-SVPWM algorithm is zero. In order to reduce the computational effort and model 

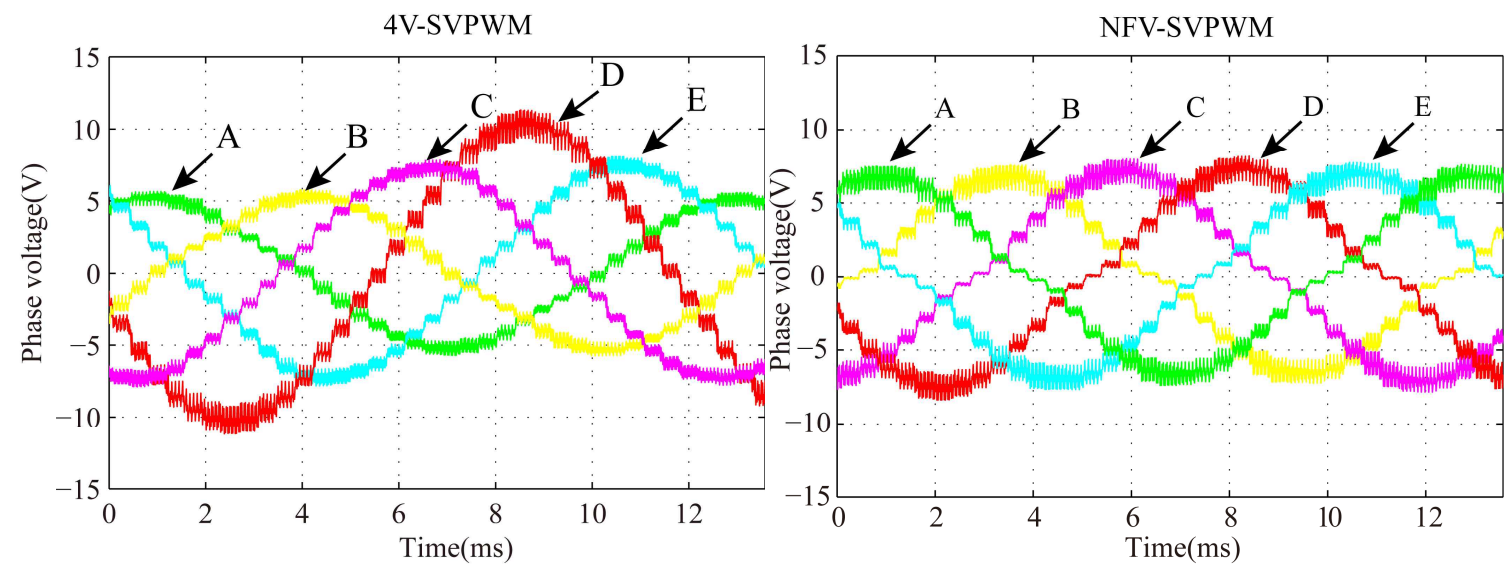

Fig. 10. Output phase voltages for $\mathbf{V}_{\text {ref }}^{\alpha \beta}=8.5 \mathrm{e}^{j \omega t}(\mathrm{~V}), \omega=518.1(\mathrm{rad} / \mathrm{s})$ under unbalanced load conditions. From left to right: 4V-SVPWM, NFV-SVPWM.
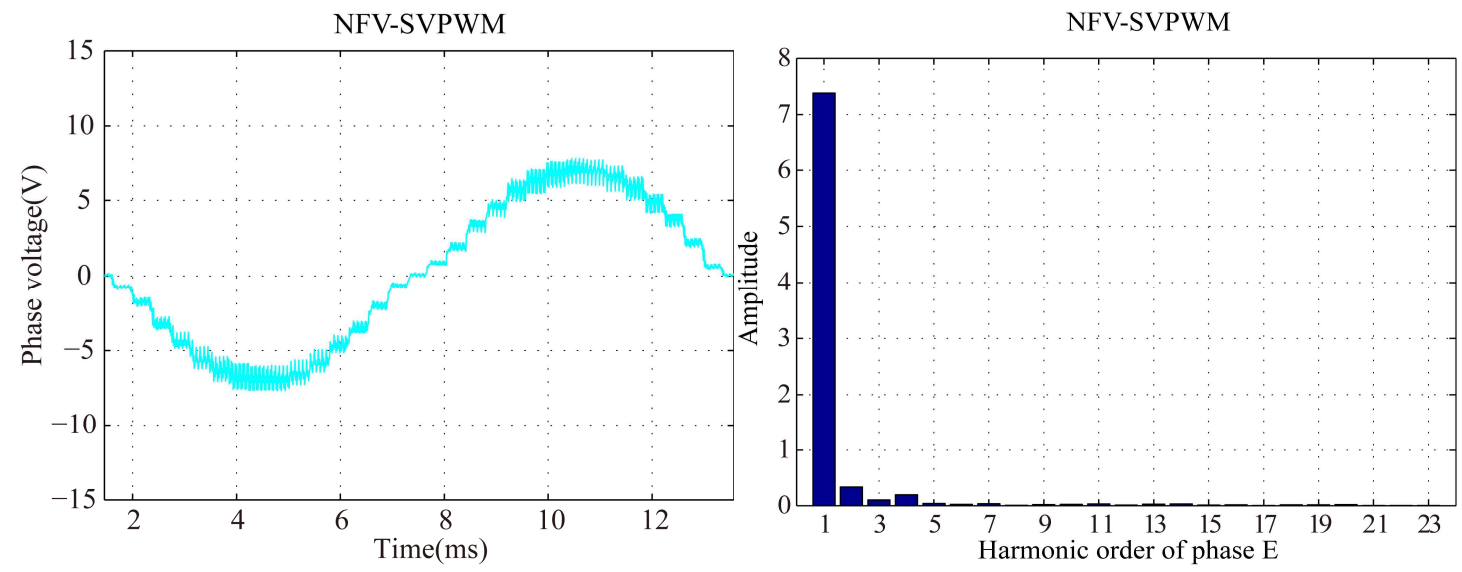

Fig. 11. Phase voltage E and FFT analysis in NFV-SVPWM algorithm.

industrial applications more analogously, the applying times of the switching vectors are calculated thirty-two times in a period of $\mathbf{V}_{\text {ref }}$. The PWM switching frequency is set to 13.2 $\mathrm{kHz}$. The output phase voltages in the experiments are shown in Fig. 10, and the FFT analysis of phase voltage E is shown in Fig. 11. The results reveal that the proposed NFV-SVPWM algorithm is able to output five symmetrical phase voltages under extreme unbalanced load conditions, and eliminate the $(10 \mathrm{k} \pm 3)$ th harmonics of the phase voltages. The amplitudes of the output phase voltages in the NFV-SVPWM algorithm are smaller than those of $\mathbf{V}_{\text {ref }}$.

This is due to the existence of the collector-emitter saturation voltage of the IGBTs. The phase voltages in Fig. 10 and 11 are filtered by low-pass filters with the same cutoff frequency of $3 \mathrm{kHz}$ to facilitate observation.

\section{CONCLUSIONS}

The proposed NFV-SVPWM algorithm based on a five-phase six-leg inverter can output symmetrical phase voltages under unbalanced load conditions, which is not possible for the conventional SVPWM algorithms based on the five-phase five-leg inverters. The cause of the extra harmonics in the phase voltages is analyzed, and an $x y$ coordinate system orthogonal to the $\alpha \beta z$ coordinate system is introduced to eliminate the low-order harmonics in the output phase voltages. Thus, there are no low-order harmonics such as the 3rd, 7th, etc. in the output phase voltages for the NFV-SVPWM algorithm. The digital implementation of the NFV-SVPWM algorithm is investigated, and the optimal approach with reduced complexity and low execution time is given. A comparison of the proposed algorithm and other existing PWM algorithms is also provided. The switching characteristics and voltage THD of the NFV-SVPWM algorithm are as good as those of the 4V-SVPWM algorithm. However, the maximum modulation index of the NFV-SVPWM algorithm is reduced by $5.15 \%$ in the linear modulation region, and algorithm complexity and memory requirement of it increase. The effectiveness of the proposed NFV-SVPWM algorithm has been validated by the simulation and experimental results. The basic principle in this paper can be easily extended to other inverters with different phase numbers. 


\section{APPENDIX A}

In order to calculate the maximum modulation index of the NFV-SVPWM algorithm in the linear modulation region, it is assumed that $\mathbf{V}_{\text {ref }}$ maps into polyhedron I of triangular prism 1 in the $\alpha \beta z$ coordinate system. In that case, $\mathbf{V}_{25}, \mathbf{V}_{24}, \mathbf{V}_{16}, \mathbf{V}_{57}, \mathbf{V}_{61}$ are selected as nonzero switching vectors. The objective function is defined as follows:

$$
f=\sqrt{\left(V_{\alpha}^{o}\right)^{2}+\left(V_{\beta}^{o}\right)^{2}}
$$

where $V_{\alpha}^{o}$ and $V_{\beta}^{o}$ denote the $\alpha$ and $\beta$ components of the synthesized voltage space vector in a PWM switching period respectively. The goal is to find the maximum value of $f$ under the constraint conditions $\left\{\begin{array}{l}V_{x}^{o}=0 \\ V_{y}^{o}=0 \\ V_{z}^{o}=0 \\ 0 \leq T_{25}, T_{24}, T_{16}, T_{57}, T_{61} \\ T_{25}+T_{24}+T_{16}+T_{57}+T_{61} \leq 1\end{array}\right.$,

where $V_{x}^{o}, V_{y}^{o}$, and $V_{z}^{o}$ denote the $x, y$, and $z$ components of the synthesized voltage space vector in a PWM switching period respectively.

Using the "Optimization Toolbox" in Matlab, the constrained maximum value of $f$ can be obtained. And the maximum modulation index of the NFV-SVPWM algorithm in the linear modulation region is calculated by

$$
M=f_{\max } \cos \frac{\alpha}{2} /\left(V_{d} / 2\right) \approx 1 .
$$

\section{ACKNOWLEDGMENTS}

This work was supported in part by the 863 Plan of China under Project 2011AA11A261, in part by National Natural Science Foundation of China under Project 51077026 and 51377033 .

\section{REFERENCES}

[1] E. Levi, "Multiphase electric machines for variable-speed applications," IEEE Trans. Ind. Electron., Vol. 55, No. 5, pp. 1893-1909, May 2008.

[2] O. Lopez, D. Dujic, M. Jones, F. D. Freijedo, J. Doval-Gandoy, and E. Levi, "Multidimensional two-level multiphase space vector PWM algorithm and its comparison with multifrequency space vector PWM method," IEEE Trans. Ind. Electron., Vol. 58, No. 2, pp. 465-475, Feb. 2011.

[3] P. Zheng, Y. Sui, J. Zhao, C. Tong, T. A. Lipo, and A. Wang, "Investigation of a novel five-phase modular permanent-magnet in-wheel motor," IEEE Trans. Magn., Vol. 47, No. 10, pp. 4084-4087, Oct. 2011.

[4] O. Lopez, J. Alvarez, J. Doval-Gandoy, and F. D. Freijedo, "Multilevel multiphase space vector PWM algorithm,"
IEEE Trans. Ind. Electron., Vol. 55, No. 5, pp. 1933-1942, May 2008.

[5] P. Zheng, F. Wu, Y. Sui, P. Wang, Y. Lei, and H. Wang, "Harmonic analysis and fault-tolerant capability of a semi-12-phase permanent-magnet synchronous machine used for EVs," Energies, Vol. 5, No. 9, pp. 3586-3607, Sep. 2012.

[6] R. Gregor, F. Barrero, S. L. Toral, M. J. Duran, M. R. Arahal, J. Prieto, and J. L. Mora, "Predictive-space vector PWM current control method for asymmetrical dual three-phase induction motor drives," IET Trans. Electric Power Application, Vol. 4, No. 1, pp. 26-34, Jan. 2010.

[7] O. Lopez, J. Alvarez, J. Doval-Gandoy, and F. D. Freijedo, "Multilevel multiphase space vector PWM Algorithm with switching state redundancy," IEEE Trans. Ind. Electron., Vol. 56, No. 3, pp. 792-804, Mar. 2009.

[8] F. Barrero, M. R. Arahal, R. Gregor, S. Toral, and M. J. Duran, "One-step modulation predictive current control method for the asymmetrical dual three-phase induction machine," IEEE Trans. Ind. Electron., Vol. 56, No. 6, pp. 1974-1983, Jun. 2009.

[9] D. Hadiouche, L. Baghli, and A. Rezzoug, "Space-vector PWM techniques for dual three-phase AC machine: analysis, performance evaluation, and DSP implementation," IEEE Trans. Ind. Appl., Vol. 42, No. 4, pp. 1112-1122, Jul. 2006.

[10] Q. Fei, Z. Deng, X. Wang, and X Li, "A control strategy of novel five-phase six-leg switching power amplifiers applied in magnetic levitating bearing systems," Proceeding of the CSEE, Vol. 32, No. 9, pp. 124-131, Mar. 2012.

[11] O. Dordevic, E. Levi, and M. Jones, "A vector space decomposition based space vector PWM algorithm for a three-level seven-phase voltage source inverter," IEEE Trans. Power Electron., Vol. 28, No. 2, pp. 637-649, Feb. 2013.

[12] L. Li, D. Czarkowski, Y. Liu, and P. Pillay, "Multilevel selective harmonic elimination PWM technique in series-connected voltage inverters," IEEE Trans. Ind. Appl., Vol. 36, No. 1, pp. 160-170, Jan. 2000.

[13] B. A. Welchko, T. A. Lipo, T. M. Jahns, and S. E. Schulz, "Fault tolerant three-phase AC motor drive topologies: a comparison of features, cost, and limitations," IEEE Trans. Power Electron., Vol. 19, No. 4, pp. 1108-1116, Jul. 2004.

[14] R. L. A. Ribeiro, C. B. Jacobina, A. M. N. Lima, E. R. C. da Silva, "A strategy for improving reliability of motor drive systems using a four-leg three-phase converter," in proceedings of the Applied Power Electronics Conference and Exposition, pp. 37-41, Anaheim, Mar. 2001.

[15] M. Beltrao De Rossiter Correa, C. B. Jacobina, E. R. Cabral da Silva, and A. M. N. Lima, "An induction motor drive system with improved fault tolerance," IEEE Trans. Ind. Appl., Vol. 37, No. 3, pp. 873-879, May 2001.

[16] H.-M. Ryu, J.-H. Kim, and S.-K. Sul, "Analysis of multiphase space vector pulse-width modulation based on multiple d-q spaces concept," IEEE Trans. Power Electron., Vol. 20, No. 6, pp. 1364-1371, Nov. 2005.

[17] Y. Zhao and T. A. Lipo, "Space vector PWM control of dual three-phase induction machine using vector space decomposition," IEEE Trans. Ind. Appl., Vol. 31, No. 5, pp. 1100-1109, Sep. 1995.

[18] D. Dujic, M. Jones, E. Levi, J. Prieto, and F. Barrero, "Switching ripple characteristics of space vector PWM schemes for five-phase two-level voltage source inverters-Part 1: flux harmonic distortion factors," IEEE Trans. Ind. Electron., Vol. 58, No. 7, pp. 2789-2798, Jul. 2011. 
[19] M. Jones, D. Dujic, E. Levi, J. Prieto, and F. Barrero, "Switching ripple characteristics of space vector PWM schemes for five-phase two-level voltage source inverters-Part 2: current ripple," IEEE Trans. Ind. Electron., Vol. 58, No. 7, pp. 2799-2808, Jul. 2011.

[20] J. Prieto, M. Jones, F. Barrero, E. Levi, and S. Toral, "Comparative analysis of discontinuous and continuous PWM techniques in VSI-fed five-phase induction motor," IEEE Trans. Ind. Electron., Vol. 58, No. 12, pp. 5324-5335, Dec. 2011.

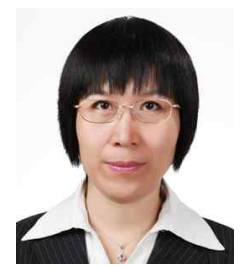

Ping Zheng (M'04-SM'05) received her B.S., M.S., and Ph.D. degrees from the Harbin Institute of Technology, Harbin, China, in 1992, 1995, and 1999, respectively. Since 1995, she has been with Harbin Institute of Technology, where she has been a Professor since 2005. She is a Member of the IEEE IAS Electric Machines Committee, IEEE Industry Applications Society and International Compumag Society. She is the author or coauthor of more than 140 published refereed technical papers and four books. She also holds 30 Chinese invention patents. Prof. Zheng was the recipient of more than 20 technical awards including the "China Youth Science and Technology Award" by the Organization Department of the Communist Party of China, in 2009. Her current research interests include electric machines and control, hybrid electric vehicles, and unconventional electromagnetic devices.

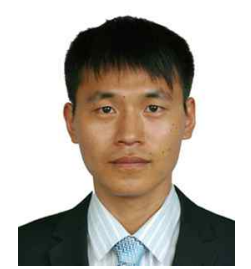

Pengfei Wang received his B.S. and M.S. degrees in Electrical Engineering from the Harbin Institute of Technology, Harbin, China, in 2007 and 2009, respectively, where he is currently working toward his Ph.D. degree. He is the author or coauthor of 7 published papers. His current research interests include fault-tolerant permanent-magnet synchronous machines, and the control strategies of multiphase machines under healthy and post-fault conditions.

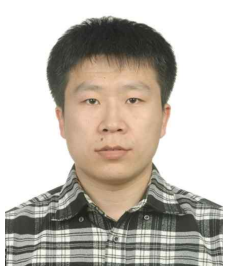

Yi Sui received his B.S. and M.S. degrees in Electrical Engineering from the Harbin Institute of Technology, Harbin, China, in 2009 and 2011, respectively, where he is currently working toward his Ph.D. degree. $\mathrm{He}$ is the author or coauthor of 15 published papers. His current research interests include the fault-tolerant permanent-magnet synchronous machine systems used in pure electric vehicles, permanent-magnet linear machines, and the high performance servo machine systems used in unconventional areas.

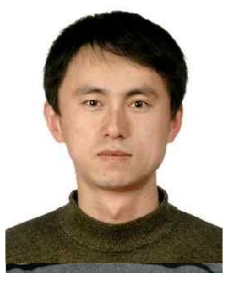

Chengde Tong received his B.S., M.S., and $\mathrm{Ph} . \mathrm{D}$. degrees in Electrical Engineering from the Harbin Institute of Technology, Harbin, China, in 2007, 2009 and 2013, respectively. He is currently a Lecturer with Department of Electrical Engineering, Harbin Institute of Technology. He is the author or coauthor of more than 30 published papers. His current research interests include electric drives and the energy management of hybrid electric vehicles, free-piston Stirling engines and permanent-magnet linear machines.

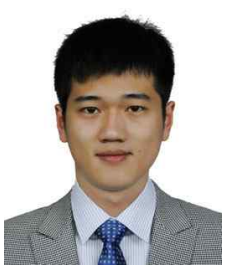

Fan Wu received his B.S. and M.S. degrees in Electrical Engineering from the Harbin Institute of Technology, Harbin, China, in 2010 and 2012, respectively, where he is currently working toward his Ph.D. degree. $\mathrm{He}$ is the author or coauthor of 14 published papers. His current research interests include electromagnetic design for electrical machines, including analytical analysis, finite element analysis and prototyping.

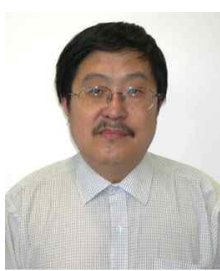

Tiecai Li received his B.S. and M.S. degrees from the Harbin Institute of Technology, Harbin, China, in 1977 and 1990, respectively. He is currently a Professor with the Harbin Institute of Technology. His current research interests include motor drives and control, integrated motor systems, information appliances. intelligent computer interface, and network 